\title{
Más allá del mundo: imaginación transtemporal para un cierto modo de habitar los confines
}

\section{El mundo y lo mundial: modos de leer, funcionamientos, motivaciones}

¿Por qué hablar del tiempo si estamos hablando del mundo? Pero antes: ¿de qué hablamos cuando hablamos de mundo en sede literario cultural?

Itinerarios, caminos, trayectos, errancias, flujos. La narrativa latinoamericana de finales del siglo XX y comienzos del XXI ha encontrado en esas figuras espaciales uno de sus motivos fundamentales, si no el principal. En sintonía con las artes (sobre todo en formato de instalaciones o intervenciones, pero también en pinturas), la narrativa tendió a focalizar aquellas historias en las que predominan los viajes, los traslados, las migraciones. Como rasgo particular, a diferencia de otros momentos en los que emergieron con rapidez los relatos de viaje, en este caso los desplazamientos son multidireccionales, arman líneas curvas y rectas, son reacios a una lógica que no sea la del puro movimiento, abarcan y amplían ilimitadamente el mundo. Como rasgo similar al de esos otros momentos previos, muchos de ellos tienen elementos documentales o los simulan, ya sea porque son crónicas o se organizan con la forma del diario, ya sea porque son del orden de lo autoficcional o porque lo emulan. Ni las diferencias ni las similitudes son menores. Por un lado, si bien siempre hay un elemento de localización fuerte en las narrativas sobre desplazamientos, también hay en el conjunto más reciente un cierto rasgo deslocalizador, en la medida en que el impulso o la necesidad de traslado excede las circunstancias locales o es ampliamente compartido; de allí la multidireccionalidad, de allí lo abarcativo. Por otro lado, la ampliación del mundo en el conjunto de esas historias, al igual que el impulso generalizado a escala mundial, remiten una vez más al modo en que los discursos de la cultura, tanto ficcionales como documentales, se vinculan con las circunstancias políticas y económicas, y también con las tecnológicas, que a la vez propician, por medio de sus propios discursos y prácticas, cierto tipo de intereses narrativos por sobre otros. Y así como el discurso de la modernización, por ejemplo, puso en el centro a la ciudad, o el de la colonización a los viajes transatlánticos y a las tierras ignotas, el discurso de la globalización puso en el centro, podríamos decir, una idea 
diferente de mundo: amplio, accesible real o virtualmente, expansivo, cognoscible, incluso hospitalario. No era un mundo que había que descubrir o que había que explorar, tampoco un mundo al que había que admirar o del que había que salir, sino un mundo al que se podía llegar, un mundo disponible.

En esa misma dirección fue que desde los estudios literarios se retomó la noción de "literatura mundial" propuesta por Goethe en 1827 y que, siguiendo alguna de sus derivas (teóricas, sociológicas, pedagógicas), diferentes críticos contribuyeron a su reemergencia y expansión. Más allá del recorrido, de los aportes, aun de los reparos, lo que me interesa es subrayar la alineación entre este tipo de producción crítica, que incluso daría lugar a lo que se conoce como World Literature Studies y tiene plafón institucional, y la producción de cierto tipo de narrativa, no solo por su inclinación temática, sino también por su difusión, sus intercambios y sus posibilidades de circulación. Con vistas al argumento que busco elaborar acá, quiero distinguir, por consiguiente, entre los tres sentidos involucrados en la noción de literatura mundial, en tanto se trata de una literatura del mundo y sobre el mundo. Por un lado, la literatura mundial como modo de leer, perspectiva ligada a los estudios literarios $\mathrm{y}$, que, en la instancia actual, podríamos datar desde el fin del siglo XX, básicamente a partir de los polémicos aportes de Pascale Casanova y Franco Moretti y, en el campo latinoamericano, de la incisiva compilación de Ignacio Sánchez Prado. ${ }^{1}$ Por otro lado, se trata de lo que llamo funcionamiento literario mundial, en el que también resuena el diagnóstico de Goethe en su archicitada frase de 1827 acerca de la insuficiencia de lo nacional para pensar la literatura y a lo que un par de décadas después se refieren Marx y Engels, comentarios ambos que despuntan la relación entre lecturas, lenguas y mercado a través de una circulación (de nombres, títulos, contenidos, géneros, formas, estilos, etcétera) inevitablemente transnacional, cuyo horizonte es mundial y cuyos alcances son inesperados; si bien este funcionamiento mundial involucra textos y autores, no se detiene en el trazo fino de las textualidades, sino que su terreno privilegiado es el de las prácticas culturales, con mayor o menor carga política y económica. Finalmente,

1 Es muy conocido el conjunto de textos inaugurales de la reemergencia de la literatura mundial a comienzos del siglo XXI, principalmente los de Franco Moretti, "Conjectures on World Literature" (2000) y "More conjectures on World Literature" (2003), y Pascale Casanova, La República Mundial de las Letras (1999). Además, fue un importante aporte la inflexión pedagógica de la cuestión de David Damrosch en su What is World Literature? (2003) y la apertura propuesta en el volumen compilado por Christopher Prendergast, Debating World Literature (2004). Una discusión pionera e incisiva sobre la situación de América Latina en los estudios de literatura mundial fue organizada por Ignacio Sánchez Prado en América Latina en la literatura mundial (2006). 
en la línea en la que inicié este ensayo, puede entenderse la literatura mundial como motivación, es decir como impulso y a la vez como motivo (en esa acepción básica que le dio Tomaschevsky en 1925), recorriendo diversos niveles, entre otros el temático, el lingüístico y el argumental. Solo en ciertas circunstancias y bajo ciertas condiciones esos tres sentidos se imbrican haciendo la noción de literatura mundial tan productiva para revisar los protocolos de la crítica literaria como para repensar los términos de lo mundial. ${ }^{2}$

Ahora bien: ¿qué ocurre cuando la relación o la sintonía entre esos sentidos de la literatura mundial se debilita, cuando la validez general de la noción de mundo entra en crisis y es cuestionada? ¿Qué repercusiones tiene tal situación en cada uno de esos sentidos? ¿Qué queda de lo mundial y cuáles son las derivas de la literatura mundial tras el desajuste de los planteos teóricos, críticos y metodológicos respecto de los discursos y las prácticas del plano político y económico? Es a raíz de estos interrogantes donde la distinción entre los tres sentidos que esbocé me resulta operativamente necesaria para pensar sus decantaciones en el momento actual y sus desafíos a futuro.

A esta altura, es inherente a la literatura una posibilidad de proyección mundial que se confronta con un paradigma nacional o local mayormente restrictivo y que la consolidación desigual del mercado de libros ha acelerado vertiginosamente (en algunos casos subsanando las desigualdades y en otros profundizándolas); en tanto funcionamiento, si atendemos a las prácticas de corte tecnológico, la literatura mundial excede sin dudas el umbral de lo postglobal. Como puede notarse, el funcionamiento "mundial" de la literatura se superpone con una vertiente del modo de leer "mundial", en la medida en que es la crítica la que detecta, rastrea y describe recorridos, flujos, circulaciones literarias. Y esa suerte de marco teórico crítico mundializador, muchas veces con un sesgo excesivamente sociológico, ya está incorporado a los estudios críticos, más allá de los World Literature Studies y de su institucionalización. Eso no obsta a que se siga sosteniendo el derecho y la aspiración a formar parte

2 Doy solo un ejemplo que me parece fundamental pensar desde toda su dimensión mundial y que siempre ha sido abordado sesgadamente: el momento romántico de mediados del siglo XIX en el Río de la Plata, que triangula Europa occidental, en particular Francia, con Estados Unidos y con América latina: entre la década de 1830 y la de 1850 puede observarse un funcionamiento (la circulación en tanto mecanismo de consagración y de mercado: traducciones, publicaciones folletinescas, etc.) y una motivación (los viajes y la exploración territorial) que hacen converger en la imagen del "desierto" configurada por Esteban Echeverría y por Domingo F. Sarmiento a Chateaubriand (Atala) y a Fenimore Cooper (The Prairie, The Last of the Mohicans). 
de ese mundo en el que la literatura circula con mayor visibilidad, tal como se observa en los debates del latinoamericanismo, que conllevan la otra vertiente del modo de leer en clave mundial. Solo que el corolario de ese gesto contemporáneo es haber asumido la idea de un mundo al que habría que ampliar y del cual hay que denunciar la jerarquización propia de la relación entre centros y periferias o una ironía intrínseca a lo global o cualquier tipo de exclusión; pero hacerlo implica aceptar, aun cuando se la combata, la lógica de un mundo único (como si fuera un retorno materialista del universalismo de mediados del siglo XX). Sostener en cambio la coexistencia de varios mundos, que muchas veces entran en contacto y se intersecan o coinciden o colisionan, intensificar la configuración de esos mundos desde una posición particular, me parece que sigue siendo un desafío mayor que el gesto aspiracional de la inclusión en una literatura mundial. Llegamos así al tercer sentido: si la globalización, tal como hemos dicho, sintonizó los postulados de la literatura mundial con los discursos y las prácticas políticas y propició entonces lo mundial como modo de leer, fue sobre todo porque, además de acelerar el funcionamiento mundial de la literatura, potenció lo mundial literario como motivación. La confianza en los tránsitos, los flujos, las movilizaciones, la apertura implicada en lo global, junto con la desconfianza y la sensación de insuficiencia ante los paradigmas nacionales, fue fundamental en este proceso, tal como lo expliqué al comienzo. Asimismo, lo fue el giro documental que tuvo lugar en las últimas décadas y que puede pensarse vis-à-vis los discursos sobre literatura mundial; en ese giro documental, los motivos del viaje en todas sus manifestaciones han sido una tendencia poderosa para una narrativa con un componente ficcional muy diluido.

En la actualidad, con la reemergencia generalizada de discursos y prácticas políticas y económicas antiglobales, esa confianza en la movilidad, esa entrega a un mundo relativamente hospitalario está en crisis, de allí el debilitamiento de la motivación implicada en una literatura mundial. Y de allí, también, la detección de nuevos motivos en la narrativa y la búsqueda de nuevas herramientas críticas.

En este punto en el que confirmamos que la literatura mundial como funcionamiento es parte de los fenómenos literarios, que como modo de leer ha decantado y se ha independizado de los World Literature Studies y de su institucionalización, y que como motivación se ha debilitado, es donde querría enfatizar que si algo distingue a la crítica actual es la necesidad de acercarse a los objetos sin un marco previo rígido para, en cambio, hacerlo con una batería conceptual variada que permita disponer de los diversos elementos que sean requeridos por cada objeto en su abordaje. Apuesto, por lo tanto, a una crítica instrumental que, con este punto de partida, construya sus teorizaciones 
y organice sus propias lecturas. Por eso mismo, vamos a hablar del tiempo cuando estamos hablando de mundo.

\section{Más allá del mundo: transtemporalidad, aceleración y desaceleración}

Al menos como tendencia visible en la narrativa del Cono Sur, podríamos afirmar que la imaginación literaria que acompaña la crisis de la noción de "el mundo" y "lo mundial" no es de orden espacial. A la profusa narrativa de viajes, tanto ficcional como documental, en la que predominaban tránsitos y flujos espaciales, no se la confronta con reclusiones o confinamientos. Tampoco hay proyecciones planetarias o intergalácticas, o sea la creación de otros mundos que compensen la crisis de este. Y sobre todo, y a diferencia de lo que ha ocurrido en los discursos políticos y económicos, no parece haber, por contraste con una imaginación global, un retorno narrativo a la imaginación nacional. En cambio, sugiero, la crisis de la imaginación espacial global, que fue la que predominó en la narrativa de las últimas décadas, está acechada por el tiempo. Solo que ya no se trata de aquel tiempo que marcó las tramas narrativas del siglo XIX, cuando reinaba la novela y con ella el tiempo cronológico; ya no estamos ante el relato del progreso, ni ante una de sus variantes novelescas preferidas: el ascenso y la decadencia. Tampoco ante el tiempo cuyas alteraciones modernistas de principios del siglo XX o las experimentaciones de los 60 conllevaban la necesidad de su reconstrucción lineal. Las grandes novelas del realismo y del modernismo hicieron del tiempo, de hecho, el sostén de sus tramas.

En cambio, en la contemporaneidad, quiero llamar la atención sobre una concepción temporal diferente: tiempos que conviven, se superponen y se confunden, tiempos que se discontinúan, se aceleran, se descomponen y se repiten. Una contemporaneidad cuya imaginación es transtemporal y que, por lo tanto, da lugar a la heterocronía y la altertemporalidad. Esa, propongo, es la imaginación postglobal: la que propone sus elaboraciones o resoluciones narrativas por medio del tiempo. Más todavía, y estrictamente en esto me quiero detener: una imaginación que encuentra en el tiempo la salida para los problemas planteados en y por el espacio, en y por el mundo. La imaginación literaria de un mundo transtemporal.

Me estoy refiriendo a un conjunto de novelas latinoamericanas del Cono Sur en las que la noción de tiempo es casi un principio constructivo. Novelas todas que trabajan con la aceleración. Una aceleración impulsada por la guerra total, por la invasión política o por la invasión ambiental, por el desastre 
ecológico, por el hambre o el caos social. Novelas de aceleración positiva, como Quema (2015) de Ariadna Castellarnau (escritora española radicada hace casi una década en la Argentina, que ganó con este libro el Premio Casa de las Américas), Los restos (2014) de Betina Keizman (argentina radicada durante aproximadamente el mismo lapso en Chile, donde ejerce la docencia universitaria), Cataratas (2015) de Hernán Vanoli (argentino que vive en la Argentina, sociólogo) o Mal de época (2017) de María Sonia Cristoff (argentina y docente universitaria de escritura creativa). Pero también novelas de aceleración negativa, como Leñador (2013) de Mike Wilson (chileno-norteamericano que vivió en la Argentina) o Distancia de rescate (2014) de Samantha Schweblin (argentina que habita hace unos años en Berlín). En todos los casos, algo ha ocurrido, no se sabe con certeza qué, y el mundo ha cambiado para siempre. En todos los casos, también, hay traslados y desplazamientos. Pero la posibilidad de habitar esos nuevos pedazos de mundo (provisorios, incómodos, insatisfactorios, amenazantes) implica una cierta desmundialización, en la medida en que acotan el mundo en lugar de ampliarlo, en la medida en que parecen protegerse de él antes que buscar en él refugio, en la medida en que lo desrealizan y ya no se lo reconoce. Desmundialización: o bien retorno a la pura naturaleza o bien cambio total de orden o bien completo extrañamiento. De allí que muchas veces, también, se produzca un borramiento gradual de las referencias espaciales.

Si el caso de la aceleración positiva es más evidente por la aceleración del ritmo narrativo o por la proliferación de temporalidades, como en los textos que mencioné, el caso de la desaceleración negativa es igualmente potente en su inflexión temporal de lo que resta del mundo. ${ }^{3}$ Mientras en Leñador de Mike Wilson el efecto de la detención del tiempo es su descomposición en partículas mínimas, ya que la narración se ve demorada permanentemente por la descripción y la explicación, en Distancia de rescate de Samanta Schweblin se apuesta a una repetición cada vez más minuciosa de las acciones como conjura contra el devenir de la historia narrada, como si la repetición con variaciones pudiera alterar el curso de la historia y crear una temporalidad alternativa. Cada una a su manera, ambas novelas plantean tramas espaciales cuyos

3 Si ponemos en sintonía lo que llamo novelas de aceleración positiva con las teorías político económicas aceleracionistas, encontramos en ellas la misma tensión que provocan estas: si el aceleracionismo supone que las capacidades productivas y tecnológicas deben ser liberadas más allá de las limitaciones impuestas por el capitalismo para dejarlo atrás y llegar a la expansión hacia un postcapitalismo globalizado (Williams/Srnicek 2017: 47), la hipótesis de las tramas y su textualidad nos permiten pensar en los efectos liberadores del aceleracionismo o, para decirlo con las palabras de uno de sus críticos más fuertes, de la "catástrofe" que implica "la intensificación del ritmo de producción y de explotación” (Berardi 2017: 69). 
conflictos se elaboran a partir de la desaceleración temporal, ya sea por la vía de la descomposición o de la altertemporalidad: ambas desaceleran el paso del tiempo, lo ralentan, lo demoran, retrasan su avance. En lo que resta de este ensayo, voy a enfocarme en una de las novelas de esto que llamo novelas de aceleración negativa. Me refiero a Leñador de Mike Wilson y la descomposición del tiempo cronológico que practica a lo largo del relato.

\section{Descomposición del tiempo en Leñador de Mike Wilson}

Los bosques del Yukón: fríos, secos, casi árticos, solitarios, arduos, extraños, alejados de todo lo conocido, extremos, un confín. Es allí donde está el protagonista de esta novela haciéndose leñador, tras llegar, presumiblemente y por algunas alusiones dispersas a lo largo del relato, desde el sur del territorio americano, desde el otro extremo; y es desde allí que narra en primera persona esa experiencia. Así empieza:

Combatí en una guerra, hace décadas en un archipiélago, y combatí en el cuadrilátero, hace años en las noches de la ciudad. Fracasé en las islas y en el ring. Me fui del país, buscando alejarme de todo, de la oscuridad, del pasado, de la claustrofobia, necesitaba respirar. Veía cosas que me hacían mal, escuchaba voces, me estaba perdiendo, extraviando en mi cabeza.Hui hasta llegar a los bosques de Yukón. (Wilson 2016: 11)

El protagonista no narra el desplazamiento a través del territorio americano, no cuenta cómo lo hizo ni por qué; tampoco explica los motivos que lo llevaron a elegir como destino el Yukón. En ese trayecto puramente masculino (la guerra, el boxeo) en el que el cuerpo se confronta con lo otro (el enemigo, el contrincante), se trata, en el Yukón, de dejarlo todo atrás para volver a empezar. La percepción del nuevo territorio como una suerte de último reducto del mundo implica, precisamente, la búsqueda no solo de una nueva vida sino también de un nuevo modo de vivir, un espacio donde desprenderse de lo que está antes para aprender todo desde el comienzo.

En su libro Tiempo. La dimensión temporal y el arte de vivir (2015), Rüdiger Safranski escribe que detrás de un verdadero comienzo existe la posibilidad de una gran transformación y se pregunta por la manera en la que nos podemos deshacer de la propia historia, de lo que nos ata hacia atrás (Safranski 2017: 46). En Leñador la posibilidad de esa gran transformación es la huida al Yukón, donde en lugar de encontrar un opositor al que vencer, como en su vida previa, aprende a convivir con la pura naturaleza, para lo cual es necesario "descifrar el 
territorio" (Safranski 2017: 47). Es en ese desciframiento en el que parecería haber una apuesta a la espacialidad, donde, a través de la noción de comienzo que se configura en la novela, se horada el tiempo cronológico de la vida en el bosque. Podría decirse, de la temporalidad construida en la novela, lo mismo que dice el narrador sobre su encuentro con un alce: "Nos quedamos así, deben de haber pasado no más de unos cuatro o cinco segundos, pero el instante se extendió, duró una vida" (Wilson 2016: 69). Porque Leñador, en su desciframiento del territorio, nos entrega una suerte de manual enciclopédico: herramientas, animales, árboles, materias primas, actividades, utensilios, estrellas, enfermedades, costumbres, productos, remedios, accidentes geográficos, mitos, y mucho más. En el manual se despliega el contenido de la frase que cierra la breve apertura narrativa de la novela, tras mencionar la huida al Yukón: “Aprendí cosas” (Wilson 2016: 11). Para narrar el aprendizaje, sin embargo, ante todo se describen esas cosas que se aprenden. Y en esa descripción hecha con minucia y atenta al detalle, el tiempo de las acciones se descompone abriéndose a una temporalidad que no es ya la de la vida del protagonista sino la de las cosas. Si el instante de la mirada entre el narrador y el alce parece durar una vida, ¿cuánto dura el instante de una cosa?

La descripción en Leñador se entrega a esa temporalidad sin cronología, en la que todo se da a la vez; una temporalidad que se transforma en sucesión solo a través de su puesta en escritura. Este, el primero de la novela, es un ejemplo contundente:

Hacha. El hacha es la herramienta por excelencia del leñador. Está compuesta de dos piezas; la hoja y el cabo. La hoja es la pieza de acero templado con forma de cuña que se emplea para cortar. El cabo (o mango) es el largo de madera con el que se sujeta y empuña el hacha. La pieza de acero se compone de la cabeza, el filo y la hoja. El filo es [...] (Wilson 2016: 11)

La descripción del hacha, además de la extensa sección en la que detalla sus características, incluye tres largas secciones más: "Tradiciones", "Mantenimiento" y "Utilización”. Toda la novela, de hecho, asume esa secuencia descriptiva, suspendida por breves fragmentos narrativos que carecen de continuidad y en los que apenas se vislumbra la rutina de la vida en el bosque. ${ }^{4}$

4 En general, las herramientas siguen la secuencia de su caracterización y las entradas acerca de para qué sirve, cómo se mantiene y cómo se usa. Otro ejemplo diferente de secuencia enciclopédica tiene las siguientes entradas: Lesiones. Cortes. Congelamiento. Roturas. Para qué sirve, cómo se mantiene, cómo se usa. Asimismo, en muchas ocasiones hay reenvíos a entradas anteriores para completar la información. 
Así, la narración ya no funciona como marco o telón de fondo de la secuencia narrativa, ya no es la presentación del ambiente que permite entender a los personajes ni de los personajes que permiten entender las acciones. En cambio, a modo de manual enciclopédico, como dije, la descripción ocupa toda la novela, se hace relato, aun cuando no cuente nada y sea casi autosuficiente. Por un lado, Leñador puede leerse, a diferencia de lo que ocurre en la novela realista moderna, como una novela en la que la descripción no contribuye a hacer avanzar la trama sino que es una información plena que surge de la observación. Pero, por otro lado, Leñador puede leerse también como una suerte de registro cotidiano en el que cada módico relato sobre la vida en el bosque encierra una observación que habilita una extensa y detallada descripción que cobra autonomía. En ese punto, Leñador hace todo lo contrario de lo que hace una novela con el tiempo: en lugar de hacerlo avanzar (hacia adelante o hacia atrás), lo suspende; en lugar de acelerarlo dándole velocidad hasta llegar al desenlace, lo desacelera hasta que ya no importa. Si en las novelas que extreman la acción, como las de aventuras, que pueden transcurrir en espacios similares al Yukón, el tiempo avanza vertiginosamente y se acelera, en Leñador se desacelera y diluye toda cronología convencional. ${ }^{5}$ De allí que hable de novelas de aceleración negativa y, en ese punto, de Leñador como una novela que, por la vía de la descripción explicativa, descompone el tiempo en cada detalle. Frente al tiempo de las acciones, la temporalidad de las cosas.

Esta aceleración negativa o desaceleración, que en Leñador asume lo que llamo descomposición del tiempo cronológico, provoca efectos que exceden la dimensión novelesca. Porque la vida en el espacio de la naturaleza, con su propia temporalidad, va en contra del tiempo capitalista del reloj, de la exactitud y la productividad cronológicas (Safranski 2017: 109); quiero decir: el tiempo de la observación y la descripción, que horada el tiempo de la acción en ese mismo espacio, es también la descomposición que la temporalidad de la vida en la naturaleza más recóndita hace del tiempo capitalista. Que esa descomposición se realice como resultado del aprendizaje del modo de vida, pero también del trabajo en el espacio de la naturaleza, que sea resultado, en definitiva, del aprendizaje del "leñador", no es contradictorio sino que, por el contrario, duplica su efecto. No se trata en principio de salirse por completo del mundo para encontrar una temporalidad alternativa, sino de ir a sus confines naturales para horadar de a poco, ipara talar!, la cronología.

5 De hecho, hay varias novelas de Jack London que transcurren en el territorio del Yukón, entre ellas, uno de sus relatos más conocidos, Colmillo blanco (White Fang, 1906). 
Junto con la descomposición del tiempo cronológico a través de la descripción, Leñador incluye por lo menos dos representaciones de un modo diferente de contar el tiempo, un modo natural de contar el tiempo. Una consiste en un almanaque agrícola que el protagonista y narrador lee en el campamento, como otros lo han hecho antes que él, y que registra cifras de producción, pestes, sequías, migraciones de aves, cosechas, menos a los propios leñadores ("nuestra utilidad pasa sin registro" [Wilson 2016: 85]). La otra es una de las entradas de lo que llamé manual enciclopédico y es la extensa explicación de la dendrocronología:

Dendrocronología. La dendrocronología es la ciencia que permite a los leñadores descifrar la edad (en años) de los árboles, contando el número de anillos de crecimiento visibles en los cortes transversales. [...] Leen los siglos, leen el pasado, el clima, el fuego, la sequía, los diluvios, el hielo, la ceniza y la peste. Lo leen todo hasta llegar al último aro, ahí se ven inscritos, hacha en mano, ahí leen la muerte. (Wilson 2016: 27s.)

En los dos casos, el paso del tiempo se vincula (y se cuenta y se lee) a través de la naturaleza. Solo que el almanaque lo hace incorporando el espacio del trabajo a la naturaleza, mientras el árbol lo hace conectando la vida con el territorio. De allí que el almanaque se pueda abandonar, como de hecho lo hace el leñador cuando deja el campamento para internarse aún más allá del Yukón, mientras el tiempo inscripto en los troncos es inherente a la naturaleza y cuenta la vida, como la del propio narrador, quien busca el círculo que se armó cuando llegó al lugar:

Ese anillo era el límite. Lo que yacía de ahí hacia el centro registraba otra vida, la que intento abandonar, es madera oscura, colonizada por memorias inciertas y una identidad frágil. Trazo una línea con el dedo hacia la orilla, hacia la corteza, hacia el presente. Comprendo que no hay regreso. Eso me calma, la idea de abandonar los anillos oscuros. (Wilson 2016: 101)

Dejar atrás la vida es internarse cada vez más en el territorio desconocido una vez que se lo ha aprendido todo en el espacio del trabajo. Viaje completo al revés del capitalismo, viaje hacia la materia prima, viaje al territorio de la pura vida. Al final, ya solo, completamente aislado, el leñador siente la necesidad de cortar un árbol. Cada parte de su cuerpo, cada movimiento, cada secuencia mínima de la acción son registrados en el último y largo fragmento narrativo que cierra la novela. La descripción es devuelta a la acción: acción ralentada, casi en cámara lenta, en la que el documentalismo se imbrica con la imaginación ficcional y retorna como registro exacto de la tala de un pino a la vez que como registro de una experiencia. 
A partir de estas observaciones sobre la relación entre mundo y temporalidad, no solo se puede avanzar en problemas como la relación entre experiencia y tiempo, entre vida y naturaleza, entre cuerpo y territorio, sino también explorar otras relaciones, como la que se da entre cultura y economía, entre cuerpo y trabajo o entre materia prima, producción artesanal y producción capitalista. Con su funcionamiento relativamente mundial (desde la trayectoria de su autor a su propia circulación) y a través de la puesta en práctica de un modo de leer que construye su marco teórico atendiendo a las textualidades, Leñador permite ver, casi como en un prisma, la inflexión temporal que puede asumir la motivación narrativa dimensionada política y económicamente ante la crisis de la noción de mundo entendida como espacio habitable.

\section{Bibliografía}

Berardi, Franco "Bifo" (2017): "El aceleracionismo cuestionado desde el punto de vista del cuerpo". En: Avanessian, Armen/Reis, Mauro (comps.): Aceleracionismo. Estrategias para una transición hacia el postcapitalismo. Buenos Aires: Caja Negra, pp. 69-76.

Safranski, Rüdiger (2017 [2015]): Tiempo. La dimensión temporal y el arte de vivir. Buenos Aires: Tusquets Editores.

Wilson, Mike (2016 [2013]): Leñador o ruinas continentales. Buenos Aires: Fiordo. Williams, Alex/Srnicek, Nick (2017): "Manifiesto por una política aceleracionista”. En: Avanessian, Armen/Reis, Mauro (comps.): Aceleracionismo. Estrategias para una transición hacia el postcapitalismo. Buenos Aires: Caja Negra, pp. 33-48. 